\title{
SELEÇÃO ADVERSA E INTERVENÇÃO HUMANITÁRIA: MITIGAÇÃO DE EFEITOS INDESEJÁVEIS
}

\section{ADVERSE SELECTION AND HUMANITARIAN INTERVENTION: MITIGATION OF UNDESIRED EFFECTS.}

\author{
${ }^{1}$ Leonel Eustáquio Mendes Lisboa

\section{RESUMO}

Este artigo dedica-se a analisar as posições e relações entre os atores em um cenário de possibilidade intervenção humanitária, para isso lançando mão de elementos da análise econômica. A possibilidade de intervenção humanitária analisada é aquela em que há um conflito armado não internacional entre as forças oficiais de um Estado e um grupo de combatentes não estatais interno. São tecidas considerações sobre a possível intervenção de um Estado, terceiro ao conflito, fornecendo inteligência, suprimentos, munição, logística, saúde, treinamento, armas ou mesmo combatentes. Aplica-se a este cenário a teoria do principal-agente, mecanismos de risco moral e seleção adversa, bem como, dilema de comprometimento. Este artigo sugere que uma regulação internacional, prévia, permanente e vinculante sobre a questão seria vantajosa para todos os atores envolvidos que estejam interessados na redução do sofrimento humano, desenvolvimento de diálogo e construção de estabilidade e paz.

Palavras-chave: Direito internacional, Intervenção humanitária, Seleção adversa, Teoria do principal-agente, Dilema de comprometimento

\begin{abstract}
This paper analyses the positions and relations between the players in a scenario of possibility of humanitarian intervention, using elements of economic analysis of law. The possibility of humanitarian intervention analyzed is set in a non-international armed conflict between the State forces and an internal non-State group of combatants. Considerations are drawn over the possible intervention of a third party, a State, providing intelligence, supplies, ammunition, logistics, health, training, weapons and even combatants. On such scenario this paper describes the application of principal-agent theory, moral hazard and adverse selection mechanism, as well as, commitment dilemma. This paper suggests that prior, permanent and binding international regulation over the matter would be more advantageous for all the players involved, provided that those player are interested in the reduction of human suffering, dialog development and the building peace and stability.
\end{abstract}

Keywords: International law, Humanitarian intervention, Adverse selection, Principal-agent theory, Commitment dilemma

\footnotetext{
${ }^{1}$ Mestrando em Direito na Universidade Federal de Minas Gerais - UFMG, Minas Gerais, MG. Estagiário docente bolsista do Programa de Incentivo à Formação Docente em Ciências do Estado, na Universidade Federal de Minas Gerais - UFMG, Minas Gerais, MG. E-mail: leonellisboa@live.com.
} 


\section{INTRODUÇÃO}

Estudos recentes ${ }^{1}$ têm concluído que intervenções humanitárias ${ }^{2}$ podem produzir resultados indesejados ou mesmo contrários aos esperados. Mais ainda, tem sido argumentado por alguns analistas que a realização de intervenções humanitárias pode chegar a criar uma "estrutura perversa de incentivos"3

Muitas vezes, uma intervenção humanitária feita com o objetivo de evitar o agravamento de conflitos, garantir um cessar fogo, propiciar diálogos entre as partes beligerantes, e, finalisticamente, alcançar a estabilidade e a paz, acabam por prolongar as hostilidades que, não raro, desenrolam-se de forma muito mais complexa do que antecipado. Estados que empreendem intervenções humanitárias em situações deste tipo não surpreendentemente acabam por se aprisionar em dilemas de comprometimento e realidades extremamente complexas, onerosas e perigosas. Também não é incomum que sejam questionados os efeitos gerais dessas intervenções. Perguntas relativas à necessidade ou mesmo à utilidade da intervenção vêm à tona e pressionam estes Estados. Relatórios de organizações não governamentais ou organismos internacionais, apesar de destacarem as iniciativas de alívio do sofrimento de pessoas e grupos, comumente questionam se houve algum benefício geral para a população impactada pela intervenção ou se ela teria ficado melhor caso não houvesse acontecido qualquer intervenção.

Conforme argumenta Robert W. Rauchhaus, o mínimo para a condução de uma intervenção humanitária, bem como na tomada de decisão de intervir ou não, deve ser a aplicação do credo médico, “primum non nocere”, isto é, primeiramente, não causar dano.

1 De Waal e Omaar 1994; Bloom 1999; Kuperman 2001, 2008; Maren 2002; Terry 2002; Crawford 2003; Rauchhaus 2005a e 2009; Crawford e Kuperman 2006. apud RAUCHHAUS, R. W. Principal-agent problems in humanitarian intervention: Moral hazards, adverse selection, and the commitment dilemma. International Studies Quarterly, v. 53, n. 4, p. 871, 2009.

2 Para maior clareza cabe destacar a diferença entre intervenção humanitária, humanitarian intervention no inglês e ajuda humanitária, humanitarian aid, no inglês. Enquanto o termo "ajuda humanitária" costuma ser empregado para caracterizar o conjunto de medidas tomadas para a disponibilização de recursos materiais e humanos de segurança, saúde, abrigo e alimentação, independentemente da causa desta necessidade, um desastre produzido pela natureza ou pelo elemento humano. Já a "intervenção humanitária" refere-se à intervenção em uma situação de conflito humano quando um ator externo ao conflito nele se interfere para, de maneira direta ou indireta, fornecer inteligência, suprimentos, munição, logística, saúde, treinamento, armas e/ou mesmo combatentes, ou outro recurso, a um dos grupos em conflito. Dependendo da configuração política do caso concreto, as intervenções humanitárias podem consistir em uso da força, no sentido do artigo 2.4 da Carta das Nações Unidas, condicionadas, portanto, à autorização do Conselho de Segurança, salvo a legitima defesa coletiva ou, naturalmente, a intervenção a convite do chefe de estado do Estado palco da interferência.

3 Tradução livre de "perverse incentive structure" KUPERMAN, A. J. The Moral Hazard of Humanitarian Intervention: Lessons from the Balkans. International Studies Quarterly, v. 52, n. 1, p. 49-80, 2008. apud RAUCHHAUS, R. W. op cit. p. 872. 
Contudo, além de não causar mal direto, é necessário que as intervenções humanitárias sejam pensadas de modo a não criarem cenários que gerem incentivos para o comportamento destrutivo e violador de direitos humanos e do direito humanitário.

A fim de buscar compreender este fenômeno, diversos analistas ${ }^{4}$ atribuem os resultados indesejáveis à assimetria de informações nas relações entre os atores (ou jogadores) envolvidos, que consistem em um Estado terceiro ao conflito e o grupo vitimado, assistido pela intervenção, que pode ser tanto um ator não estatal ou o próprio governo. Neste artigo adotaremos a possibilidade de intervenção em favor do grupo não estatal, a fim de melhor recortar o problema. Robert W. Rauchhaus aplica conceitos de seleção adversa à análise deste fenômeno e proporciona algumas reflexões interessantes que serão examinadas neste artigo.

Serão empregados conceitos da análise econômica e teoria dos jogos a fim de demonstrar em que medida a seleção adversa ocorre nos casos de intervenção humanitária e apresentar algumas possíveis medidas para remediar os dilemas de comprometimento e a própria assimetria de informação, como a criação de uma regulação prévia, permanente e vinculante sobre a matéria.

\section{INFORMAÇÃO ASSIMÉTRICA E TEORIA DO "PRINCIPAL-AGENTE"}

Neste tópico examinaremos a teoria do "principal-agente" que foi desenvolvida por economistas para representar e lidar com as dificuldades associadas com as situações nas quais um principal contrata um agente para realizar uma tarefa ${ }^{5}$. Esta conceituação econômica, construída para lidar com contratos de representação e agência, bem como para mandatos, entre outros baseia-se na dinâmica descrita a seguir.

De acordo com este modelo, o principal (outorgante, no mandato e proponente, no contrato de agência) e o agente (outorgado, no mandato e agente, no contrato de agência) não têm suas informações e preferências perfeitamente niveladas e alinhadas. Como no caso de um proponente e um representante comercial, ou mesmo no caso de um mandatário e um outorgado, o proponente/mandatário não acompanha as ações do representante/outorgado,

\footnotetext{
${ }^{4}$ Kuperman 2001, 2008; Maren 2002; Terry 2002; Crawford 2003, apud RAUCHHAUS, R. W. op cit. p. 872, 2009.

5 Teoria do "principal-agente" trata-se de uma tradução livre de "Principal-agent theory" que é o nome amplamente aplicado na teoria e na análise econômica para descrever a situação examinada e seus polos, bem como buscar remediar seus problemas. Outra possível tradução seria 'Teoria do outorgante-outorgado' ou Teoria do 'proponente-agente', tomando por emprestado os conceitos do direito contratual da civilística brasileira. Contudo, preferimos aqui utilizar a tradução literal a fim de evitar a confusão com a própria teoria de direito dos contratos e manter a conexão com a conceituação original.
} 
nem pode saber quais são suas ações, observando apenas o resultado delas. De forma clássica, neste jogo de informação assimétrica, o principal confia determinada tarefa ao agente e/ou lhe proporciona determinadas vantagens. Em contrapartida, o agente cumpre a tarefa que lhe é designada e/ou remete ao principal parte dos rendimentos de uma determinada atividade. Ocorre que o agente tem informação muito mais completa da realidade fática do dia a dia e controle da conduta do que o principal, além de que o principal não observa as ações do agente, por motivos de custo, limitações materiais e legais de privacidade e ajustes contratuais de autonomia nos casos concretos. A teoria econômica de principal-agente desenvolve possíveis respostas e medidas de mitigação destas desvantagens. ${ }^{6}$

Recentemente, analistas e cientistas políticos, como Gary J. Miller têm passado a aplicar este conjunto de conceitos e teorias econômicas às ciências políticas ${ }^{7}$. Segundo Miller, esta preocupação já se encontra conceituada de maneira inicial em Weber quando trata, nas relações de hierarquia política, que a autoridade está localizada em um polo da relação e a vantagem informacional, no outro.

Descreve Robert W. Rauchhaus, que na economia, os problemas de principal-agente são tradicionalmente separados entre aqueles decorrentes (i) de ação oculta, que são de risco moral e (ii) de informação oculta, que são de seleção adversa:

Nas ciências econômicas, acadêmicos têm tradicionalmente usado uma distinção entre dois tipos de problemas de principal-agente: aqueles resultantes de ações ocultas, e aqueles resultantes de informação oculta (...) Ações ocultas são o que gera risco moral; informações ocultas, em contraste, são associadas com seleção adversa. ${ }^{8}$

\subsection{RISCO MORAL}

Assim, nas situações de informação assimétrica onde há "ações ocultas" haveria risco moral para o outro jogador. Tomamos aqui a didática definição de Bierman em "Teoria dos Jogos", ao basear-se no exemplo de seguradoras. Risco moral seria: "(...) a capacidade de os compradores de seguros realizarem ações que a seguradora não pode observar e que alteram a

\footnotetext{
${ }^{6} \overline{\text { RAUCHHAUS, R. W. op cit. p. } 873 .}$

${ }^{7}$ MILLER, Gary J. The Political Evolution of Principal-Agent Models. Annual Review of Political Science, v. 8 n. 1, p. 203-225, 2005.

8 RAUCHHAUS, R. W. op cit. p. 872. Tradução livre de: "In economics, scholars have traditionally distinguished between two types of principal-agent problems: those resulting from hidden actions, and those resulting from hidden information (...) Hidden action is what generates moral hazard; hidden information, in contrast, is associated with adverse selection."
} 
quantidade do risco que eles transferem para as empresas seguradoras." ${ }^{9}$ Exemplo disso é a tendência que os novos segurados de um seguro de incêndio têm de reduzir os seus cuidados de manutenção preventiva e vistoria, bem como os donos de estabelecimentos comerciais que adquirem seguro contra assalto tendem a reduzir as precauções e medidas mitigadoras ou limitadoras de risco de assalto. Em razão disso, as seguradoras se utilizam de mecanismos de incentivo, bônus e coparticipação, para mitigar esses efeitos, o que analisaremos com mais vagar mais a diante.

Aplicando-se o conceito ao problema principal-agente, e adaptando o conceito para questões políticas, há risco moral quando o agente tem a capacidade de agir de forma indesejada pelo principal que, por sua vez, não consegue observar o seu comportamento, ou não consegue determina-lo precisamente apenas pela observação das consequências e decorrências de tal comportamento. Um exemplo disso é o comportamento de representantes comerciais ou políticos que gozam de relativa autonomia. Quanto maior sua autonomia, maior a necessidade de mecanismos de monitoramento e alinhamento entre proponente ou poder concedente (principal) e agente, a fim de mitigar o risco moral presente.

No caso de uma intervenção humanitária, consideraremos algumas vezes durante este artigo uma situação em que há um conflito armado interno em um determinado Estado. As partes do conflito armado interno, conforme acima mencionado, seriam o próprio Estado, por meio de suas forças militares oficiais, e um grupo combatente não estatal interno. Consideraremos que um Estado terceiro ao conflito tem por interesse realizar uma intervenção humanitária com fins de alcançar a redução do sofrimento humano, propiciar o diálogo e ajudar no processo de estabilização e paz locais. Para tanto este terceiro intervém apoiando o grupo não estatal com recursos que podem variar em sua natureza, como inteligência, suprimentos, munição, logística, saúde, treinamento, armas ou mesmo combatentes.

Para sistematizar esta situação, utilizaremos uma estrutura de jogo, da teoria dos jogos ${ }^{10}$. Consideremos que um jogador é o Estado que deseja intervir (principal) e o outro jogador é o grupo não estatal (agente). A sequência de eventos que descreve o jogo seria:

1. Principal faz uma proposta ao agente, colocando as condições para a intervenção.

2. Agente aceita ou rejeita as condições; rejeição encerra o jogo.

\footnotetext{
${ }^{9}$ BIERMAN, H. S.; FERNANDEZ, L. Teoria dos Jogos. 2. ed. São Paulo: Pearson Prentice Hall, 2011, p. 218.

${ }^{10}$ Fizemos aqui a opção de não estruturar o jogo como uma árvore de decisões tendo em vista que a quantidade de caminhos para a tomada de decisões tornaria o desenho por demais complexo, sem que isso implicasse em melhor condição de compreensão da questão em tela.
} 
3. Agente se comporta de maneira que não pode ser observada pelo principal.

4. Natureza determina o "estado do mundo", isto é, as consequências para o "mundo" do comportamento do agente.

5. Jogadores recebem suas recompensas.

Assim, visto que a forma que o agente se comporta não pode ser observada pelo principal, deve o principal investir e empenhar-se em construir sistemas de relatórios e monitoramento passivo e ativo dos efeitos das condutas dos agentes a fim de buscar inferir quais foram estas condutas ocultas. Destaca-se que perguntar ao agente qual foi sua conduta seria inócuo. Em jogos de informação assimétrica, quando um jogador não pode observar a jogada do outro, não pode aquele acreditar nas declarações deste sobre sua conduta, haja vista que aquele não tem como verificar a veracidade/confiabilidade da informação deste. Do ponto de vista estratégico/racional, não importa se o agente mente ou diz a verdade ao declarar sua conduta, o principal não poderá reputar crível tal declaração, visto que o agente não tem incentivos para dizer a verdade, mas pode ter incentivos para mentir.

Embora sistematize bem e através de um modelo elegante que permite alguns insights, este cenário de jogo com risco moral, defendido por Kuperman em sua obra, descreve uma configuração muito difícil de ser encontrada na realidade. Conforme demonstra Rauchhaus não é característico deste tipo de situação fática que o principal tenha problemas para identificar as condutas do agente, ao contrário, "If third parties do not recognize what is happening, it is not because they cannot see, but more likely that they do not want to see."11 De fato, as condutas de agentes que são combatentes não estatais são bastante delineadas, inclusive porque comumente os atores desta natureza tendem a fazer ações que chamam muita atenção e transmitem a mensagem de seus pleitos para a população em geral, os combatentes estatais e a sociedade internacional. Assim, não seriam as ações do agente que seriam ocultas ou difíceis de monitorar, seriam suas intenções que jazeriam ocultas.

Alguns pesquisadores alertam que, nestes casos, o conceito de risco moral pode obscurecer mais do que revelar. ${ }^{12}$ Por tudo isso, seria inadequado aplicar os conceitos de risco moral para descrever e buscar solucionar os problemas advindos de situações análogas à mencionada. Entendemos, em acordo com Rauchhaus, que o mais adequado é aplicar o conceito de seleção adversa e seus mecanismos de mitigação ao tratar de intervenções humanitárias.

\footnotetext{
${ }^{11}$ RAUCHHAUS, R. W. op cit. p. 878.

${ }^{12}$ Ibidem, p. 872.
} 


\subsection{SELEÇÃO ADVERSA}

Por sua vez, a seleção adversa, que também foi desenvolvida pela teoria econômica, foi moldada para descrever situações em que o tipo de um jogador e a qualidade do produto que oferece são ocultos. Como vimos, neste caso, oculto seria o tipo do agente e a qualidade daquilo que oferece, isso é, a sua disposição para o diálogo, o respeito a limites e a busca pela paz, no caso em tela.

Tomaremos aqui o conceito de seleção adversa, novamente em Bierman: "O comprador de um carro usado está praticando um jogo de seleção adversa, quando não sabe qual é a qualidade dos carros usados que estão à venda, mas os vendedores sabem."

Bierman vale-se aqui do popular cenário do jogo de venda de carros usados para descrever uma situação onde acontece seleção adversa. Neste jogo, descrito pela primeira vez por George Akerlof ${ }^{14}$ e que lhe rendeu, ao lado de Joseph Stiglitz, o premio Nobel de economia em 2001, apenas um dos polos da transação (vendedor) tem informação sobre a qualidade do produto (carro usado) e o outro polo (comprador) não tem como saber a qualidade do produto. Conforme descrito por Akerlof, ocorre que um comprador racional levará em consideração que não sabe a qualidade do carro e que o vendedor pretende lhe vender o carro usado de menor qualidade possível, pelo maior preço possível e, portanto sempre oferecerá lances baixos para adquirir o produto. Ora, novamente, de nada adianta perguntar ao vendedor qual a qualidade do seu produto, uma vez que ele tem todos os incentivos para declarar que seu produto é de alta qualidade, independentemente desta informação ser verdadeira ou falsa. Mesmo que diga a verdade, contudo, o comprador jamais saberá se trata-se de informação confiável ou não, porque a combinação de jogadas mais benéfica para o vendedor é aquela que é mais danosa para o comprador. Visto que um vendedor racional jamais aceitará um lance baixo por um carro de qualidade maior, somente serão vendidos os carros de pior qualidade, e, em geral, a preços baixos. Os melhores carros não circularão naquele mercado, mas em mercados paralelos, como o de amigos e parentes do vendedor, bem como o de vendedores de carros usados.

Ainda neste exemplo, o que podemos observar é que ambos jogadores ao agir racionalmente encontram um equilíbrio subótimo, sendo que seria melhor comprar um carro

\footnotetext{
${ }^{13}$ BIERMAN, H. S.; FERNANDEZ, L. Teoria dos Jogos. 2. ed. São Paulo: Pearson Prentice Hall, 2011, p. 354.

${ }^{14}$ AKERLOF, G. A. The Market for "Lemons": Quality Uncertainty and the Market Mechanism. The Quarterly Journal of Economics, v. 84, n. 3, p. 488-500, 1970.
} 
de melhor qualidade e receber um melhor preço pelo carro vendido, para comprador e vendedor, respectivamente. Este cenário que força os jogadores a um equilíbrio subótimo, é chamado por Akerlof de "mercado de limões ${ }^{15 "}$.

Decorre disso que mesmo que o principal possa livremente observar as condutas do agente, o principal não sabe dizer qual a qualidade do produto que está sendo ofertado, logo, não sabe dizer se o agente está se comportando de forma desejada ou indesejada. Como consequência, por mais que o principal identifique consequências indesejadas, não sabe dizer sobre a atribuição de tal consequência à conduta do agente, mesmo eu o principal lhe pergunte e o agente responda diretamente.

As principais implicações da aplicação do mecanismo descritivo de seleção adversa para o problema principal-agente em tela são: (i) o agente sabe quais suas intenções no conflito e sabe o que fará caso a intervenção humanitária aconteça, (ii) o principal não sabe as preferências do agente, mas pode observar o seu comportamento. Contudo, o principal oferece e se compromete com a intervenção humanitária antes e apenas depois o agente exerce seu comportamento de buscar o diálogo ou intensificar os conflitos, no novo cenário com a intervenção humanitária.

Estruturando a questão como um jogo, temos a seguinte linha do tempo:

1. Natureza determina as preferências ("qualidade" das intenções) do agente, apenas o agente observa esta jogada.

2. Principal faz uma proposta ao agente, colocando as condições para a intervenção.

3. Agente aceita ou rejeita as condições; rejeição encerra o jogo.

4. Agente se comporta de maneira que, desta vez, pode ser observada pelo principal.

5. Jogadores recebem suas recompensas.

Demonstra-se muito mais realista o conceito de informação oculta do que de ação oculta, porque, conforme já mencionado, os grupos combatentes tendem a agir de forma ostensiva e a assumir eventuais as vitórias militares que alcançam de forma a aumentar seu moral e sua legitimidade. Ademais, não haveria, pelos mesmos motivos, neste caso, custo muito elevado na observação e monitoramento de forma ativa das ações desses agente pelo principal.

\footnotetext{
15 Tradução livre de "market for lemons". "Lemon" é um termo coloquial do inglês americano para carro com defeitos preexistentes que, por sua vez, só são descobertos após a compra.
} 
Assim, um grupo que se configurasse como combatente não estatal e que identificasse como vantajosa uma intervenção humanitária tenderia, do ponto de vista racional, a aceitar a intervenção humanitária, contudo, o principal, por sua vez, estaria ajudando um grupo cujos interesses verdadeiros lhe são desconhecidos.

Além de melhor descrever a situação fática, a aplicação do conceito de seleção adversa é defensável também pelas consequências extremamente negativas do dilema do comprometimento, do qual trataremos a seguir.

\subsubsection{DILEMA DE COMPROMETIMENTO}

Seja aplicando o conceito de risco moral ou o de seleção adversa, tem-se que o principal tende a cair em situações definidas na teoria econômica como dilemas de comprometimento. Isso ocorre quando pesa severa incerteza quanto aos resultados positivos tanto do comprometimento quanto do não comprometimento, mas sabe-se dos riscos bastante possíveis destes resultados negativos.

Conforme já demonstraram inúmeros estudos das ciências econômicas ${ }^{16}$, tanto na gestão do risco atuarial quanto na descrição do comportamento econômico dos consumidores, a contratação de um seguro pode aumentar a possibilidade de que o segurado se comporte de forma mais arriscada. Um consumidor que adquiriu seguro de automóvel sente-se mais disposto a estacionar, de graça, o seu carro em uma rua mal iluminada do que pagar por um estacionamento fechado ou a dirigir de forma um pouco menos cuidadosa, bem como, a existência de um seguro desemprego compulsório e mantido pelo governo pode reduzir a urgência na busca por novo emprego por um trabalhador recém desposicionado do mercado de trabalho. ${ }^{17}$

Para reduzir estas tendências e inclinações, e assim evitar reduzir a probabilidade destes comportamentos a um patamar administrável, seguradoras e governos têm desenvolvido, especialmente dos anos 1960 em diante, mecanismos de controle e de incentivo a comportamentos de menor risco e proatividade, bem como sistemas de punição e, em último caso, suspensão/anulação/extinção do benefício de proteção ofertado.

Logo, seria de se imaginar que uma solução disponível para o principal, no caso de intervenção humanitária, fosse usar dos mesmos remédios para levar seu agente a evitar

\footnotetext{
${ }^{16}$ PAULY 1968, ARROW 1970, ZECKHAUSER 1970, 1971, CHEUNG 1969, ROSS 1973, STIGLITZ 1974 e DEMBE and BODEN 2000 apud RAUCHHAUS, R. W. op cit. p. $874 .{ }^{17}$ Idem.
} 
comportamentos indesejados e de aumento de risco ou de belicosidade. Contudo, existe uma diferença fundamental nos cenários classicamente descritos pelas ciências econômicas e as intervenções humanitárias.

No caso de seguros, por exemplo, o ator social que concretamente toma as medidas de correção/punição é institucionalizado como uma autoridade externa e distinta daquela que oferece benefícios e proteção ao segurado. Essa institucionalização dissocia o ator que corrige e pune abusos daquele que oferece proteção, assim, uma medida que dificulte o acesso a determinados recursos disponibilizados, exija do segurado uma contrapartida financeira e/ou comportamental, ou que anule a proteção do seguro no caso de determinada conduta comissiva, ou mesmo omissiva, que aumente o risco da seguradora, não atinge o segurado como uma injustiça ou uma decisão meramente política casuística da seguradora, ao contrário, tal medida é interpretada como uma inerência institucional a este tipo de contrato.

Entretanto, a situação no direito internacional é fundamentalmente diferente, em razão da ausência de uma autoridade fiscalizatória/punitiva das condutas indesejadas do agente não estar dissociada em entes diferentes, mas fundida uma vez que o mesmo Estado que realiza a intervenção humanitária também seria o único, ou o mais interessado e materialmente capaz, em posição de aplicar restrições, exigir contrapartidas e, em último caso, punir. O que ocorre, contudo, é que uma atitude desse tipo não seria interpretada pelo agente e por terceiros como uma inerência a este tipo de relação, mas como uma decisão meramente política e casuística. Isso decorre, entre outros, como destaca Rauchhaus, da natureza autoimpositiva e autorrealizadora de tais métodos de controle e desincentivo:

\begin{abstract}
"Infelizmente, os mesmos mecanismos que vinculam um terceiro a intervir em caso de uma crise humanitária, podem dificultar ou tornar impossível a punição de uma minoria local que tenha se tornado cobeligerante ou provocadora. (...) Logo, quando um terceiro intervém ou ameaça intervir, podem surgir oportunidades para aproveitadores e 'caroneiros'. Em contraste, se um terceiro falha em se comprometer suficientemente para intervir, as partes beligerantes podem vir a desconsiderar suas demandas." 18
\end{abstract}

Outro elemento geral e comum ao se tratar de intervenções humanitárias é que, em razão do alto custo orçamentário, reputacional e militar, muitas vezes contados em vidas de soldados perdidos pelo principal e/ou milhões de dólares, líderes políticos que se dispõem a

\footnotetext{
18 RAUCHHAUS, R. W. op cit. p. 873. Tradução livre de: "Unfortunately, the same mechanisms that will commit a third party to intervene in the event of a humanitarian crisis may make it difficult or impossible to punish a domestic minority that has become a cobelligerent or provocateur. (...) Thus, once a third party intervenes or threatens to intervene, opportunities for free-riding and exploitation may emerge. In contrast, if a third party fails to commit sufficiently to intervening, the belligerents may discount the third party's demands."
} 
mobilizar recursos para estas missões frequentemente pintam as coisas em preto e branco ${ }^{19}$ de forma a fazer parecer não haver opção para a comunidade de tomadores de decisões e o contingente político que os suporta. Transformar uma situação passível de intervenção em um imperativo moral absoluto tende a ser uma ferramenta superutilizada por líderes políticos.

O grande problema desta abordagem de uma situação de conflito, além, é claro, dos demais efeitos negativos da simplificação e do reducionismo de questões muito mais complexas do que um embate entre o bem e o mal, é a armadilha axiológica na qual tais líderes políticos se colocam.

Como poderia o principal, após algum período de intervenção humanitária em uma situação tão clara e imperativa de bem contra o mal, declarar a punição do grupo que apoia, a remoção do auxílio prestado ou o bloqueio deste(s) grupo(s) aos recursos de inteligência, suprimentos, munição, logística, saúde, treinamento, armas ou mesmo combatentes porque estes próprios recursos estariam incentivando o agente a comportar-se de forma indesejável, irresponsável e contrária à paz e o diálogo?

Em razão disso, mesmo que o principal notifique o agente e declare que suspenderá ou sustará a intervenção e a disponibilização dos recursos caso determinadas condutas não cessem ou sejam repetidas, tais notificações ou declarações serão consideradas não críveis pelo agente. $\mathrm{O}$ agente sabe do dilema de comprometimento no qual o principal se encontra e pode utilizar-se disso.

Além de tudo visto até aqui, é preciso ressalvar que estes mecanismos e estas descrições de estratégias de decisões a fazer se referem a hipóteses nas quais o principal possui sincero e confesso propósito de desenvolvimento de diálogo, redução do sofrimento humano e busca da paz sustentável, Como na intervenção humanitária no Kossovo, liderada por Clinton e na Líbia, liderada por Obama, tais intervenções visam também, ou mesmo principalmente, a extensão da esfera de influência político-militar do principal ou a ajuda a um aliado, entre outros. ${ }^{20}$

\subsubsection{SINALIZAÇÃO E SELEÇÃO}

Tendo tudo acima referido em consideração, chamamos a atenção para a principal consequência da adoção de um conceito (risco moral) ou outro (seleção adversa) no caso de intervenções humanitárias. Caso entenda-se que se trata de situação de risco moral, a

\footnotetext{
${ }^{19}$ RAUCHHAUS, R. W. op cit. p. 879.

${ }^{20}$ RAUCHHAUS, R. W. op cit. p. 880.
} 
orientação de comportamento do principal deverá ser a de monitoramento do comportamento do agente e da punição deste quando se comportar de maneira indesejada ou de forma contrária à redução do sofrimento humano, desenvolvimento de diálogo entre as partes beligerantes e busca pela paz. Entretanto, conforme vimos, o agente tenderá a considerar qualquer ameaça de punição como ameaça não crível, haja vista o dilema de comprometimento acima tratado.

Logo, seja por melhor adequar-se às situações de fato em que as condutas do agente são claras e de conhecimento comum, mas suas intencionalidades são ocultas, seja pela ordem pragmática de que a aplicação de punição é, em geral, impraticável, a concepção de seleção adversa se mostra mais vantajosa e apta a apresentar soluções úteis às questões em tela. Para mitigar os problemas inerentes à seleção adversa, a melhor conduta do comprador é investigar a qualidade do produto, isto é, o principal deverá selecionar de forma ativa e cuidadosa o grupo em favor do qual intervirá, conforme Rauchhaus menciona:

"Ao invés de clamar por melhoras no monitoramento, quando um garantia de segurança já está efetiva, seleção adversa sugere que os tomadores de decisão política se foquem em melhores sistemas de seleção, contratos mais sofisticados e formas mais efetivas de punição."21

Isso nos coloca diante de uma situação interessante. Conforme demonstrou Akerlof, em 1970, existiriam alguns mecanismos por meios dos quais os vendedores podem sinalizar, de maneira crível, a qualidade de seus produtos. Spence, em 1973, aborda a sinalização em mercados de trabalho com grande quantidade de ruído e Rothschild e Stiglitz, em 1976, por sua vez, analisaram a sinalização em mercados de seguros ${ }^{22}$. O que todos estes trabalhos indicaram é que dependendo da estrutura de mercado o vendedor pode conseguir sinalizar de forma crível a qualidade de seus produtos, da mesma forma que, na hipótese de uma intervenção humanitária, o agente pode conseguir sinalizar ao principal as suas intencionalidades.

\section{MEDIDAS POSSÍVEIS}

\footnotetext{
${ }^{21}$ RAUCHHAUS, R. W. op cit. p. 872. Tradução livre de: "Instead of calling for improved monitoring once the security guarantee is in place, adverse selection suggests that policymakers must focus on better screening, more sophisticated contracts, and more effective punishments."

${ }^{22}$ AKERLOF 1970, SPENCE 1973 e ROTHSCHILD and STIGLITZ 1976 apud RAUCHHAUS, R. W. Principal-agent problems in humanitarian intervention: Moral hazards, adverse selection, and the commitment dilemma. International Studies Quarterly, v. 53, n. 4, p. 881, 2009.
} 
Como solução, ou medida de mitigação, dos problemas decorrentes do mecanismo de seleção adversa que opera no caso de intervenção humanitária, sugere Rauchhaus que, o principal desenvolva um processo de seleção ativa a fim de buscar determinar qual a intencionalidade e a intensidade destas intenções de redução do sofrimento humano, busca de diálogo e construção/condução de um processo de paz.

Além disso, sugere Rauchhaus ao fim de seu artigo, a adoção destas medidas de monitoramento, inclusive para a observação de sinalizações, bem como a melhora dos “contratos" entre principal e agente, em uma intervenção humanitária, de forma que o agente saiba claramente quais as regras que deve seguir e quais as consequências previstas nestes casos.

Contudo, da mesma forma que existem bancos grandes demais para falir, os agentes sabem que quanto maior o esforço havido para convencer a população e os tomadores de decisão a realizar a intervenção, maior a impraticabilidade de uma punição mediante cobrança de multa ou suspensão da disponibilização dos recursos da intervenção. Logo, ameaças de punição não seriam críveis.

Cabe aqui reforçar um ponto relevante: decorre do parágrafo anterior que, quanto mais controversa uma intervenção militar, maior a confiança do agente em contrariar impunemente o principal. Podemos também considerar que uma intervenção pode ser mais, ou menos, controversa em razão do grupo que busca apoiar, isso implica um incentivo perverso no seguinte sentido: Quanto menos disposto um grupo estiver a obedecer e submeter-se às regras do jogo de um principal, mais controversa será a aprovação da interversão humanitária, o que forçará a adoção de um discurso mais simplificador que, por sua vez, gerará um dilema de comprometimento ainda mais envolvente. Logo, dentro do limite para a adesão do principal, há um incentivo ao agente para que não forneça informações confiáveis e não se comporte de forma confiável.

\subsection{REGULAÇÃo PREVIA E GERAL DA INTERVENÇÃO HUMANITÁRIA E SELEÇÃO/TRIAGEM}

É no ponto anterior que Rauchhaus conclui seu artigo. Entendemos que o próximo passo na construção de respostas para a mitigação dos efeitos negativos da seleção adversa seja a criação de um sistema que se beneficie do mecanismo de sinalização e de adaptação dos agentes sinalizadores. 
Pesquisas têm indicado ${ }^{23}$ que há tendência de que, quando há a criação de normas fixas, claras e prévias a uma seleção, com o tempo, estas influenciam as escolhas que os jogadores fazem durante seu processo de preparação. Isso pode ser verificado claramente nos casos de seleção para uma vaga de trabalho ou numa universidade. Regras claras, fixas e duradouras tendem a moldar o mercado de trabalho e o contingente de estudantes em busca de uma posição ou vaga em determinado curso universitário. A fim de mitigar os efeitos da seleção adversa, são fixadas regras permanentes e claras que condicionam a própria formação e preparação dos candidatos, uma vez que, caso se pergunte ao candidato sobre sua compatibilidade com a posição buscada e ele afirme ser compatível, o selecionador não pode confiar nesta resposta, haja vista o conjunto de incentivos que o candidato tem para sempre responder afirmativamente a esta questão. Supera-se isso através da imposição de requisitos objetivos que demonstram um mínimo de comprometimento com determinados valores e práticas, bem como, não raro, acabam por condicionar e moldar a própria consciência e padrão de conduta do candidato.

Assim, entendemos que uma medida concreta para a mitigação destes riscos e o condicionamento dos candidatos a agentes em intervenções humanitárias, seria a aprovação de uma resolução no Conselho de Segurança e na Assembleia Geral, de forma a vincular ambos os órgãos e todos os Estados-membros e disciplinar requisitos claros e mínimos para que um grupo possa receber, direta ou indiretamente, recursos decorrentes da intervenção humanitária, quais sejam:

a) Declarar-se vinculado e demonstrar medidas concretas de observância e treinamento no respeito ao artigo $3^{\circ}$ comum das Convenções de Genebra de $1949^{24}$;

\footnotetext{
${ }^{23}$ STIGLITZ 1974 e DEMBE and BODEN 2000 apud RAUCHHAUS, R. W. op cit. p. 874.

${ }^{24}$ Artigo $3^{\circ}$ comum das Convenções de Genebra de 1949:
}

No caso de conflito armado que não apresente um caráter internacional e que ocorra no território de uma das Altas Potências contratantes, cada uma das Partes no conflito será obrigada a aplicar pelo menos as seguintes disposições:

1) As pessoas que tomem parte diretamente nas hostilidades, incluídos os membros das forças armadas que tenham deposto as armas e as pessoas que tenham sido postas fora de combate por doença, ferimento, detenção ou por qualquer outra causa, serão, em todas as circunstâncias, tratadas com humanidade, sem nenhuma distinção de caráter desfavorável baseada na raça, cor, religião ou crença, sexo, nascimento ou fortuna, ou qualquer critério análogo.

Para este efeito, são e manter-se-ão proibidas, em qualquer ocasião e lugar, relativamente às pessoas acima mencionadas:

a) As ofensas contra a vida e integridade física, especialmente o homicídio sob todas as formas, as mutilações, os tratamentos cruéis, torturas e suplícios;

b) A tomada de reféns;

c) As ofensas à dignidade das pessoas, especialmente os tratamentos humilhantes e degradantes;

d) As condenações proferidas e as execuções efetuada sem prévio julgamento, realizado por um tribunal regularmente constituído, que ofereça todas as garantias judiciais reconhecidas como indispensáveis pelos povos civilizados.

2) Os feridos e doentes serão recolhidos e tratados. 
b) Declarar-se vinculado e demonstrar medidas concretas de observância e treinamento no respeito aos Protocolos Adicionais I, II e III;

c) Declarar-se vinculado e demonstrar medidas concretas de observância e treinamento no respeito a instrumentos internacionais de proteção de direitos humanos, conforme o caso; e

d) Declarar-se vinculado e submetido de forma irrevogável à jurisdição e competência do Tribunal Penal Internacional.

A seleção dos instrumentos e corpos jurídicos aos quais o grupo não estatal teria que manifestar unilateralmente sua vinculação e respeito deve ser cuidadosamente trabalhada e seguramente seria objeto de longo debate nas Nações Unidas. A lista acima mencionada é meramente ilustrativa, mas aponta na direção de um mínimo a ser exigido dos grupos que receberão recursos de outro Estado para auxiliar-lhes em um conflito.

Além do já referido, uma resolução neste sentido seria também muito útil para restringir a possibilidade de intervenções humanitárias usadas por potências internacionais como fachada para operações de intrusão na vida política de um Estado e de um povo, o que violaria, ao invés de afirmar, o seu direito a autodeterminação.

\section{CONCLUSÃO}

Este artigo consiste em uma análise da aplicação de conceitos da análise econômica a problemas do direito internacional público e do direito internacional humanitário. O que demonstramos é que em situações de intervenção humanitária, quando um Estado, terceiro a um conflito armado não internacional, intervém em apoio a um grupo interno de combatentes não estatais, tal intervenção pode gerar diversos efeitos indesejados ou mesmo contrários a seus objetivos fundamentais em razão da assimetria de informação entre os atores envolvidos.

Concluímos que alguns destes aspectos negativos decorrem da seleção adversa e do dilema de comprometimento que ocorrem nestes casos e apresentamos possíveis medidas para mitigar tais efeitos negativos.

De forma ainda inicial, visto que é necessário empregar ainda bastante reflexão e investigação ao tema, nos parece que através de uma resolução geral e duradoura sobre o tema

Um organismo humanitário imparcial, como a Comissão Internacional da Cruz Vermelha, poderá oferecer os seus serviços às Partes no conflito.

As Partes no conflito esforçar-se-ão também por pôr em vigor por meio de acordos especiais todas ou parte das restantes disposições da presente Convenção.

A aplicação das disposições precedentes não afetar o estatuto jurídico das Partes no conflito. 
seria possível condicionar o próprio comportamento de grupos não estatais e, com o tempo, forçar mudanças de conduta e consciência de forma a obter sua vinculação a obrigações internacionais mínimas de caráter penal e humanitário internacional. Entendemos também que isso mitigaria a realização deste tipo de intervenção como mera fachada para expedientes de intrusão nos assuntos internos dos Estados.

\section{REFERÊNCIAS}

\subsection{ARTIGOS}

AKERLOF, G. A. The Market for "Lemons": Quality Uncertainty and the Market Mechanism. The Quarterly Journal of Economics, v. 84, n. 3, p. 488-500, 1970.

MILLER, Gary J. The Political Evolution of Principal-Agent Models. Annual Review of Political Science, v. 8 n. 1, p. 203-225, 2005.

RAUCHHAUS, R. W. Principal-agent problems in humanitarian intervention: Moral hazards, adverse selection, and the commitment dilemma. International Studies Quarterly, v. 53, n. 4, p. 876, 2009.

\subsection{LIVROS}

BIERMAN, H. S.; FERNANDEZ, L. Teoria dos Jogos. 2. ed. São Paulo: Pearson Prentice Hall, 2011.

DINH, Nguyen Quoc, DAILLIER, Patrick e PELLET, Alain. Direito Internacional Público.

Ed. 2. Lisboa: Fundação Calouste Gulbenkian. 2003.

FRANCK, Thomas, CHESTERMAN, Simon e MALONE, David. Law and Practice of United Nations. Ed. 1. New York: Oxford University Press.

\subsection{CONVENÇÕES E TRATADOS}

Carta das Nações Unidas, São Francisco, 1945.

Convenção de Genebra para Melhorar a Situação dos Feridos e dos Enfermos nas Forças Armadas em Campanha, 1949.

Convenção de Genebra para Melhorar a Situação dos Feridos, dos Enfermos e dos Náufragos das Forças Armadas no Mar, 1949.

Convenção de Genebra Relativa ao Tratamento dos Prisioneiros de Guerra, 1949.

Convenção de Genebra Relativa à Proteção das Pessoas Civis em Tempo de Guerra e Protocolos Adicionais, 1949. 